\title{
An Investigation of Pre-Service Teachers Using Mobile and Wearable Devices for Emotion Recognition and Social Sharing of Emotion to Support Emotion Regulation in mCSCL Environments
}

\author{
Suthanit Wetcho \\ Faculty of Education, Chulalongkorn University, Thailand \\ ORCID: 0000-0003-4668-528X \\ Jaitip Na-Songkhla \\ Faculty of Education, Chulalongkorn University, Thailand \\ ORCID: 0000-0001-5306-7688
}

Received: 17 Nov 2021

Accepted: 23 Jan 2022

\begin{abstract}
In the era of a workforce driven by automation and artificial intelligence, social and emotional skills are becoming increasingly relevant to online learning environments. Since social-emotional learning may be defined as a vital component of the learning process in professional instructional design practices, online learners not only need to develop the ability to apply their knowledge, attitudes, and skills but also to understand and manage their emotions. In which setting and achieving positive goals through social interaction, sharing feelings, and developing empathy for others can help with the process. This paper outlines the possibility of using emotion recognition, and social sharing of emotion techniques to support the regulation of emotion in pre-service teacher education. This study aimed to investigate pre-service teachers' emotion recognition tools acquired by emotion tracker and physiological signals based on their perceptions (without a concrete experience and knowledge). Moreover, the predictive ability was examined along with the relationships between emotion recognition, social sharing of emotion, and emotion regulation. Finally, we investigated emotion adjustment techniques that can be adapted into mobile computer-supported collaborative learning (mCSCL). In this study, 183 pre-service teachers from three different teacher-education institutions in Thailand, were voluntarily participated based on convenience sampling. The results of a self-report via online survey revealed that most pre-service teachers own at least one of the mobile technologies e.g., smartphones, tablets, or laptops. However, there is an increasing number of additional gadgets and wearable devices like EarPods and smartwatches. At the current time, it is nearly impossible to use of the loT and other wearable devices. According to their subjective impressions in which corresponded to emotion recognition in the scientific literature, Heart rate (HR) and Heart rate variability (HRV) have recognized the most possibilities for emotion detection among physiological signals. Regarding regression analysis, the two-predictor models of emotion recognition and the social sharing of emotion were also able to account for $31 \%$ of the variance in emotion regulation, $\mathrm{p}<.001, \mathrm{R} 2=.31$, and $95 \% \mathrm{Cl}[.70, .77]$. In addition, the $\mathrm{mCSCL}$ applications and the importance of these variables in different collaboration levels are also discussed.
\end{abstract}

Keywords: social emotional learning, emotion recognition, social sharing of emotion, emotion regulation, $\mathrm{mCSCL}$ 


\section{INTRODUCTION}

In the current era, social-emotional skills are becoming increasingly relevant to online learning environments. In addition, online learners need to develop the ability to understand and manage emotions, as well as setting and achieving positive goals through social interaction, feelings, and showing empathy towards others. The original socioemotional selectivity theory (Carstensen, 1992) helped us to shape the idea that social motives fall into 1 of 2 categories, which are the acquisition of knowledge and its relation to emotion regulation. This is applicable in accordance with previous research (Carstensen et al., 2003; Dudley \& Multhaup, 2005). As a result, the key factor for success consists not only of the acquisition of knowledge, but also the regulation of emotion in a social world. It was found in previous studies that students of teacher-education faced socioemotional challenges, in which both individual and social elements of collaborative situations create intrinsic group dynamics. Therefore, the use of self-regulation became a socially shared-regulation (Järvenoja \& Järvelä, 2009). In addition, recent evidence addressed the importance of teachers' perceptions of emotional authenticity, which matters to students. Consequently, teachers gaining an understanding of how they regulate their own emotions is necessary (Keller \& Becker, 2020). As a rapid growing of mobile technology, a survey of 63.8 million people in Thailand (National Statistical Office, 2020) revealed that there were 60.5 million mobile phone users (94.8\%) which $86.4 \%$ of population were using smartphone and there were 49.7 million internet users (77.8\%) in 2020. Moreover, mobile technologies seem to be an importance factor to support teaching and learning and professional development, e.g. Kearney and Maher (2019) examined the pre-service teachers use of mobile technologies to support professional learning network and Liu et al. (2021) who proposed a mobile team-based competition approach to situate students in social interactions.

In order to relate the theoretical possibilities of emotion identification, sharing, and regulation to the realworld practical environment, by combining the theoretical with the predicative factors and revealing the potential of employing technology and some techniques. Therefore, this paper outlines the possibility of using emotion recognition to support emotion regulation in pre-service teacher education by using an emotion tracker and the physiological signals acquired from mobile and wearable devices. Moreover, we aim to examine the predicative ability and the links between emotion recognition, social sharing of emotion, and emotion regulation. In addition to these, techniques which can be adapted in the computer-supported collaborative learning will also be examined. The present study is guided by the following research questions:

1. RQ1: What are the emotion trackers and the physiological signals acquired from mobile and wearable devices that pre-service teachers use based on their perceptions for emotion recognition?

2. RQ2: Are emotion recognition and the social sharing of emotion the predicative variables for emotion regulation?

3. RQ3: What are the emotion adjustment techniques regarding emotion recognition, social sharing of emotion, and emotion regulation which can be adapted in the mobile computer-supported collaborative learning?

As a result of the emerging of mobile learning, there are new learning designs which support collaboration and learning. Emotion recognition, sharing, and regulation are listed as an emotional experience within the learning process. More recent attention has been placed on the provision of using mobile computersupported collaborative learning $(\mathrm{mCSCL})$ together with emotion recognition, sharing, and regulation.

\section{Mobile Computer-Supported Collaborative Learning (mCSCL)}

The demand for digital technology in technology-enhanced learning provides a development of social practices in which learning is mediated by collaboration. Hence, learners move from their individual learning towards collaborative learning. The proof concept of computer-supported collaborative learning (CSCL) resides in an interdisciplinary dimension. It refers to the activities that take place through peer's interactions with the support of information and communication technologies (ICT) for the purpose of learning. Additionally, there are many ways that computer-mediated networks support social interaction, for example, by adding cooperation, collaboration into learning and knowledge the building process. To help facilitate the 
sharing and creation of knowledge and expertise, group interactions can take place in various learning environments such as virtual or blended/hybrid learning environments (Resta \& Laferrière, 2007; Suthers, 2012). Due to the development of mobile learning via handheld technologies, mobile computer-supported collaborative learning ( $\mathrm{mCSCL}$ ) has been developed. The concept of $\mathrm{mCSCL}$ can be defined as using mobile devices to enhance learning and interaction which results in characteristics of mobile devices and collaborative or cooperative learning being integrated (Sung et al., 2017). Researchers Hsu and Ching (2013) stated four major types of $\mathrm{mCSCL}$, including: assigning learning tasks, facilitating communication and interaction, providing feedback for group learning and instructor teaching, managing and regulating interaction processes. The $\mathrm{mCSCL}$ concept is also related to the socio-cognitive, it was revealed in the study of Augustsson (2010) that web 2.0, which is used for students' reflection on the thoughts and emotions of both themselves and others, supported individual students' identification and awareness in relation to self and integrated group work. A study conducted by Näykki et al. (2017) exhibited the involvement of student teachers' in collaborative learning on socio-cognitive and socio-emotional monitoring processes by using active, script-based discussions in a CSCL setting. In addition, it was found by Jeong et al. (2019) that the effects of technology and pedagogy are varied and depend on the modes of collaboration. Collaborations can be viewed as difference levels of involvement with a partner, working together in achieving their goals. The five levels of collaboration are listed as follows: networking (loosely defined and little communication and all decisions are made independently), cooperation, coordination, coalition, and collaboration (strongest with mutual trust characteristics (Frey et al., 2006). This study further observed pre-service teachers and what they might have seen in the difference of importance between emotion recognition, social sharing of emotion, and emotion regulation at different levels of collaboration.

\section{Emotion Recognition, Sharing, and Regulation}

Salovey and Mayer (1990) who first used the term "emotional intelligence" to describe a set of skills that contribute to the accurate appraisal and expression of emotion in oneself and others. Emotional intelligence consists of three categories of adaptive abilities, including: appraisal and expression of emotion, regulation of emotion, and the utilization of emotion in solving problems. The effectiveness of regulation of selfemotion, and emotion in others, is related to the use of feelings to motivate, plan, and achieve in one's life. It was later proposed by Mayer et al. (2016) that the four-branch model of emotional intelligence helps to retain a membership status and maintain a desired reputation within a group. The model is comprised of perceiving emotion, understanding emotions, facilitating thought using emotion, and managing emotions. Our study explored emotion recognition and the sharing of emotion in a social context as key variables of emotional experience which aid in generating positive emotion regulation. In addition, not only is selfperspective reflected, but also the effect of social situations and environments, both of which must be considered.

\section{Emotion Recognition}

Emotion recognition is defined as the recognizing of emotion in faces and further understanding the meanings of emotion in words, as well as managing feelings among others (Salovey \& Mayer, 1990). There are several agreements on the definition of the term "emotion". As depicted by Kołakowska et al. (2014), "emotion" is a reaction that lasts for seconds or minutes, while "mood" is an emotional state that lasts for hours or days and is dependent on personality. So, the term "emotion recognition" was used as an automatic classification of a user's temporal, current, emotional state. Emotion recognition is also related to humancomputer interactions, and it was stated by Cowie et al. (2001) that automatic emotion recognizers can be generated in order to negotiate human-computer interactions. Human emotion recognition can be acquired via several techniques or methods depending on various inputs. The main category is human physical signals and physio-logical signals gathered from multi-sensory receptors. An example of physical signals (external) would be following facial expressions (visual), speech (vocal), gestures, and posture (kinesthetic). Physiological signals (internal), which can be used as interpretations, are as follows; electroencephalogram (EEG), temperature (T), electro-cardiogram (ECG), electromyogram (EMG), galvanic skin response (GSR), respiration (RSP), etc. (Nasoz et al., 2003; Sarprasatham, 2015; Shu et al., 2018). Researchers used various ways to distinguish the accuracy of emotion recognition abilities. In addition, Lyusin and Ovsyannikova (2016) 
revealed the possible techniques that could be used to measure emotion recognition through video recordings, photographs, video tapes, voice recordings, speech, descriptions of situations, and verbal tasks.

\section{Social Sharing of Emotion}

Social sharing of emotion is defined as an involvement in the evocation of emotions in a socially shared language, and on a symbolic level (latent or indirect communications). This can take place when individuals openly communicate their emotional circumstances, feelings and reactions. There are five specific predictors regarding the interpersonal sharing of an emotion including the interest, emotional contagion, empathy and sympathy, attachment behaviors, and enhanced affection of the narrator (Rimé, 2009; Rimé et al., 1998). The ability to understand social situations and expectations is also related to interpersonal regulation of emotion, which may lead individuals to help others in shaping their affective lives. As stated by Zaki and Williams (2013), interpersonal regulation can be categorized into two types of processes; responsedependent and response-independent. Previous studies suggested the individual, interpersonal and contextual indicators which can determine the cognitive or socio-affective factors. As a result, investigation of the dynamic systems that support emotion regulation needs to be conducted (Butler \& Gross, 2009).

\section{Emotion Regulation}

Emotion regulation is the key variable of this study, which refers to the way in which people manage emotional experiences for both personal and social purposes related to emotional intelligence (Bucich \& MacCann, 2019; Thompson et al., 2008). It was stated by Heberle et al. (2020) that emotion regulation is one of the key success factors for social and emotional learning. The term emotion can be divided into multiple levels including: the state of the brain in association with the presentation or withdrawal of an incentive, the subjective experience of a feeling state, the labels or meanings attributed to a feeling state, and a behavioral manifestation such as an action or facial expression. Successful emotion regulation is also based on three major factors; reflecting out-of-control negative emotion, emotional awareness and expression, and cognitive strategies for emotion regulation (Zelkowitz \& Cole, 2016) regarding the experiential, behavioral, physiological manifestations, and goal activation (Preece et al., 2018).Previous studies have also proposed the extended process model of emotion regulation including situation selection, situation modification, attentional deployment, cognitive change, and response modulation (Gross, 2015).

Previous research has sought to explain the emotional connections in $\mathrm{MCSCL}$ contexts. A study was published on the impact of emotion awareness in computer-mediated collaboration (CMC) to engage participants in mutual emotion modeling (Molinari et al., 2013). Goal metacognitive activity that utilized motivation and emotions in the dynamic social interaction setting during collaboration was also discovered in other studies (Miller \& Hadwin, 2015). Furthermore, it was shown that emotions and identities play an essential role in collaborative learning, necessitating the development of tools for promoting emotional awareness and regulation as part of collaborative efforts (Ludvigsen, 2016). Emotion regulation in collaborative learning, according to Näykki et al. (2017), is the process of becoming aware of one's own and others' affective reactions, as well as the ability to monitor and control emotional experiences. They proposed that successful learning in both individual and group contexts requires socio-emotional group activities that characterize well-functioning and effective collaborative learning.

As mentioned in the literature review above, the topic can be best treated under three variables under the $\mathrm{mCSCL}$ environments (Figure 1): emotion recognition, the social sharing of emotion, and emotion regulation. We started the process with an examination of pre-service teachers who utilized emotion trackers and physiological signals obtained from mobile and wearable devices for emotion identification based on their perceptions. Then, as predicative factors for emotion regulation, we investigated emotion recognition and social sharing of emotion. Finally, based on their perspectives, the emotion adjustment strategies of emotion recognition, social sharing of emotion, and emotion regulation are disclosed in the environment of mobile computer-supported collaborative learning. 


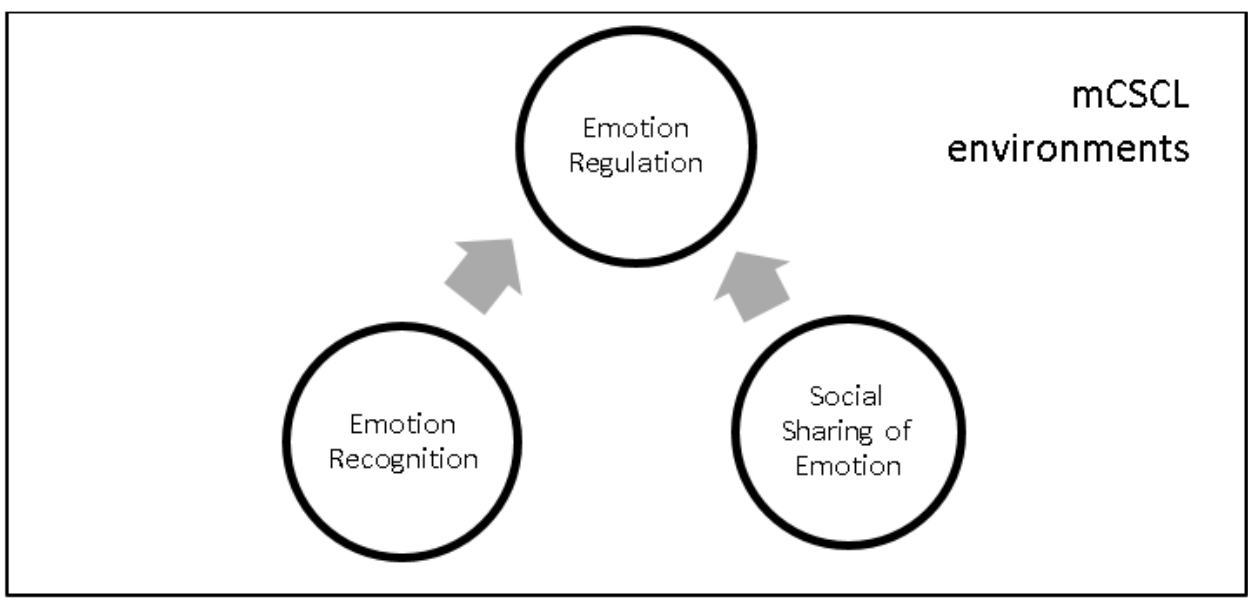

Figure 1. The framework of recognizing, social sharing, and regulating emotions in the $\mathrm{MCSCL}$ environments

\section{METHODS}

\section{Context and Participants}

In this study, pre-service teachers were voluntarily participated based on the convenience sampling method. Data was collected from faculty of Education undergraduate students from three universities using an online survey. The participants were studying in different contexts in Thailand, including Chulalongkorn University (public research university), Panyapiwat Institute of Management (private corporate university), and Ramkhamhaeng University (open university). At the end of the survey period, we removed any incomplete surveys from the participants, resulting in a final sample of 183 participants (70 males (38.3\%), 113 females (61.7\%)). Most participants were from Chulalongkorn University $(n=127)$, followed by Panyapiwat Institute of Management ( $n=22)$ and finally Ramkhamhaeng University $(n=34)$.

\section{Instruments}

To gain an insight on emotion recognition tools and their links between emotion recognition, social sharing of emotion, and emotion regulation from pre-service teachers, we employed an online survey with a quantitative approach. The survey collected demographic information as well as a set of frequencies from pre-service teachers who utilized emotion recognition from mobile and wearable devices. This was accomplished through the use of an emotion tracker and physiological data obtained via mobile and wearable devices based on their subjective impressions, without any concrete experience or knowledge of the indications used to measure these psychological signals by those technologies. Additionally, to assess emotion recognition, social sharing of emotion, and emotion regulation, we adapted an existing validated self-report scale ( 30 items) by using a 5 -point frequency Likert scale, which ranged from " 1 - never" to " 5 al-ways". The structure of the self-report in this study was comprised of 13 items of emotion recognition, which was then adapted into a 33-item emotional intelligence scale (Schutte et al., 1998). The sample questions are "When my mood changes, I see new possibilities" and "I find it hard to understand the nonverbal messages of other people*". Secondly, 9 items of emotion regulation were adapted from the cognitive emotion regulation questionnaire-and then developed into a short version made up of 18-items (CERQ-short) (Garnefski \& Kraaij, 2006), the sample of questions were "I think that basically the cause must lie within myself*" and "I think that I have to accept that this has happened". Thirdly, 8 items of social sharing of emotion were adapted from the interpersonal emotion regulation questionnaire (IERQ): Scale (Hofmann et al., 2016), the sample questions were "Because happiness is contagious, I seek out other people when I'm happy" and "When I feel elated, I seek out other people to make them happy". For additional discussion, we included questions concerning $\mathrm{mCSCL}$ apps utilized depending on three factors, as well as activities used for emotion adjustment. Also, the collaboration levels among partners were assessed by having participants estimate the level of importance of emotion recognition, social sharing of emotion, and emotion regulation on a 5-point Likert scale ranging from " 1 -not important" to " 5 -extremely important." According to the 


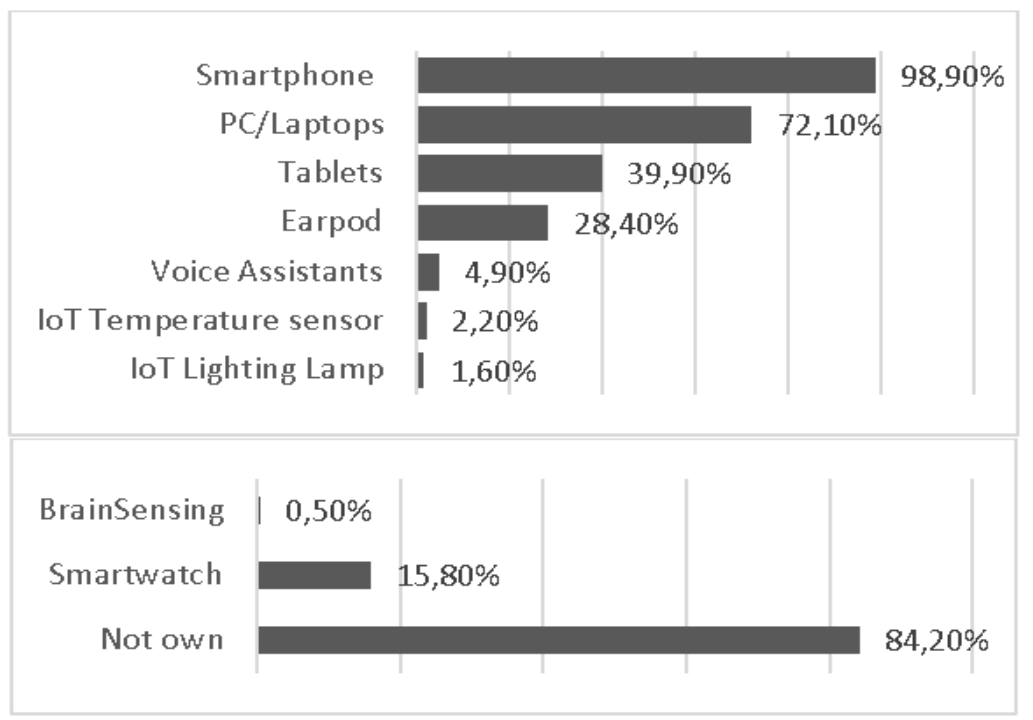

Figure 2. The frequency of participants' own devices

collaboration scale (Frey et al., 2006), the collaborations were classified into five levels, ranging from a low to high level of full collaboration (networking-collaboration). The index of item-objective congruence (IOC) was used to find the content validity. All items were judged by three experts which the qualified items were greater than 0.60 . The reliability of the instrument in the form of Cronbach's alpha coefficient was 0.703 .

\section{Data Collection and Analysis}

The survey was sent to the pre-service teachers during the first semester of their teaching practicum in school. Participants were asked to submit an online consent form before taking the survey. Prior to the analysis, univariate normality, the skewness coefficient and kurtosis coefficient of the variable were analyzed to prove normal univariate distribution. Which all variables were considered acceptable (between \pm 1 ). For the data analysis, descriptive statistical analysis (percentage, mean, and standard deviation) and multiple regression were utilized for analysis using the $\mathrm{IBM}^{\circledR}$ SPSS $^{\circledR}$ Statistics 24 software to answer both research questions.

\section{RESULTS}

\section{Research Results}

This first section presents the findings from each of the research questions.

\section{RQ1-Emotion recognition tools}

Participants were asked to report whether they owned both technological and wearable devices. The results were measured using a checklist. As depicted in Figure 2, most of the pre-service teachers in this study owned a smartphone (98.9\%) followed by a PC/Laptop (72.1\%), with the fewest amounts owning tablets (39.9\%). Interestingly, the use of Bluetooth earphones such as EarPods has increased dramatically (28.4\%). Few preservice teachers reported the use of loT devices such as temperature and lighting lamps. When it came to wearable devices, it was found that they were rarely used by pre-service teachers, with a high percentage of participants who did not own any wearable devices (84.2\%). Smart watches were below the one-third of participants in terms of ownership (15.8\%) and only one person was found to be using a brain sensing device.

The next section of the survey was concerned with which signals/elements could be used for participants' self- and others' emotion recognition without any conditions in prior concrete experience and knowledge. These results from the levels of agreement suggested that the majority of those who responded to the survey 
Table 1. Signals/elements used for emotion recognition

\begin{tabular}{|c|c|c|c|c|}
\hline \multirow{2}{*}{ Signal/elements } & \multicolumn{2}{|c|}{ Recognizing self-emotions ( $n=183$ ) } & \multicolumn{2}{|c|}{ Recognizing others' emotions $(n=183)$} \\
\hline & $\mathrm{M}$ & SD & $\mathrm{M}$ & SD \\
\hline \multicolumn{5}{|l|}{ Physical signals } \\
\hline 1.Expression & 4.34 & .80 & 4.39 & .76 \\
\hline 2.Voice/speech & 4.36 & .81 & 4.39 & .79 \\
\hline 3.Gesture/posture & 4.13 & .82 & 4.31 & .78 \\
\hline \multicolumn{5}{|l|}{ Physiological signal } \\
\hline 4. Heart rate $(H R)$ & 3.74 & 1.0 & 3.39 & .99 \\
\hline 5. Heart rate variability (HRV) & 3.65 & .99 & 3.31 & .95 \\
\hline 6. Electroencephalogram (EEG) & 3.46 & .94 & 3.26 & .98 \\
\hline 7. Temperature $(T)$ & 3.54 & .93 & 3.34 & .98 \\
\hline 8. Electrocardiogram (ECG) & 3.41 & .91 & 3.27 & .99 \\
\hline \multicolumn{5}{|l|}{ Social activity } \\
\hline 9. Text (status, captions, tweets) & 3.66 & 1.01 & 3.89 & .90 \\
\hline 10. Chats & 3.80 & .99 & 3.96 & .91 \\
\hline 11. Photos & 3.70 & 1.03 & 3.78 & 1.01 \\
\hline 12. Video stories & 3.80 & 1.03 & 3.90 & 1.03 \\
\hline 13. Emoticons & 3.65 & 1.20 & 3.73 & 1.07 \\
\hline 14. Stickers & 3.65 & 1.14 & 3.71 & 1.03 \\
\hline 15. AR emoji & 3.36 & 1.09 & 3.39 & 1.07 \\
\hline
\end{tabular}

Table 2. Pearson correlation coefficients values among three variables

\begin{tabular}{lcccccc}
\hline & $\mathrm{n}$ & $\mathrm{M}$ & $\mathrm{SD}$ & 1 & 2 & 3 \\
\hline Emotion recognition & 183 & 3.80 & .57 & 1 & & \\
Social sharing of emotion & 183 & 3.50 & .77 & $.411^{* *}$ & 1 & \\
Emotion regulation & 183 & 3.62 & .63 & $.483^{* *}$ & $.464^{* *}$ & 1 \\
\hline
\end{tabular}

**Correlation is significant at the 0.01 level (2-tailed)

strongly agreed that they mostly used physical signals e.g., expression, voice/speech, and gesture/posture to recognize their own emotions $(\mathrm{M}=4.34,4.36,4.13, \mathrm{SD}=.90, .81, .82)$, and used the following items to recognize others' emotions ( $M=4.39,4.39,4.31, S D=.76, .79, .78)$ respectively. Among the physiological signals, we found that heart rate (HR) and heart rate variability (HRV) received highest level of agreement $(\mathrm{M}=3.74,3.65, \mathrm{SD}=1.0, .99)$. In addition, participants seemed to use text (status, captions, tweets) and chats to recognize their own emotions $(M=3.66,3.80, S D=1.01, .99)$ and others' emotions $(M=3.89,3.96, S D=.90$, .91). Photos, and video stories seem to be used frequently in the emotion recognition of both self and others. Interestingly, participants reflected less using emoticons, stickers, AR emoji. Table 1 highlights the summary of agreement on the signals/elements that were used for the emotion recognition of both self- and others.

\section{RQ2-3-Predicative ability of three variables and emotion adjustment techniques}

In the next section, we aimed to examine the predicative ability and the links between emotion recognition, social sharing of emotion, and emotion regulation. This was done after the participants rated the level of frequency of three variables. The results, as seen in Table 2, found the correlation between emotion recognition, social sharing of emotions, and emotion regulation was also found to be statistically significant, $p<.01$, two-tailed. The values for all variables across cases are positively correlated $(r=.41, .48, .46)$.

Then, multiple linear regression analysis was used to develop a model for predicting emotion regulation based on the participants' emotion recognition as well as the social sharing of emotion outlined in a selfreport questionnaire. Basic descriptive statistics and regression coefficients are shown in Table 3. It was found that every of the predictor variables (emotion recognition, social sharing of emotion) had a significant $(p<.01)$ zero-order correlation with emotion regulation in the full model. The two-predictor model was able to account for $31 \%$ of the variance in emotion regulation, $\mathrm{p}<.001, \mathrm{R} 2=.31,95 \% \mathrm{Cl}[.70, .77]$. Figure 3 illustrates the partial regression plot of dependent variable (emotion regulation). The multiple regression equation takes the following form: 
Table 3. Regression analysis summary for emotion regulation

\begin{tabular}{lccccc}
\hline Variable & $\mathrm{B}$ & $95 \% \mathrm{Cl}$ & $\beta$ & $\mathrm{t}$ & $\mathrm{p}$ \\
\hline Constant & 1.237 & {$[.70, .77]$} & & 4.557 & .000 \\
Emotion recognition & .386 & {$[.24, .53]$} & .351 & 5.201 & .000 \\
Social sharing of emotion & .262 & {$[.15, .37]$} & .319 & 4.728 & .000 \\
\hline
\end{tabular}

Note. $\mathrm{R} 2=.31(\mathrm{~N}=183, \mathrm{p}<.01), \mathrm{Cl}$ : Confidence interval for $\mathrm{B}$
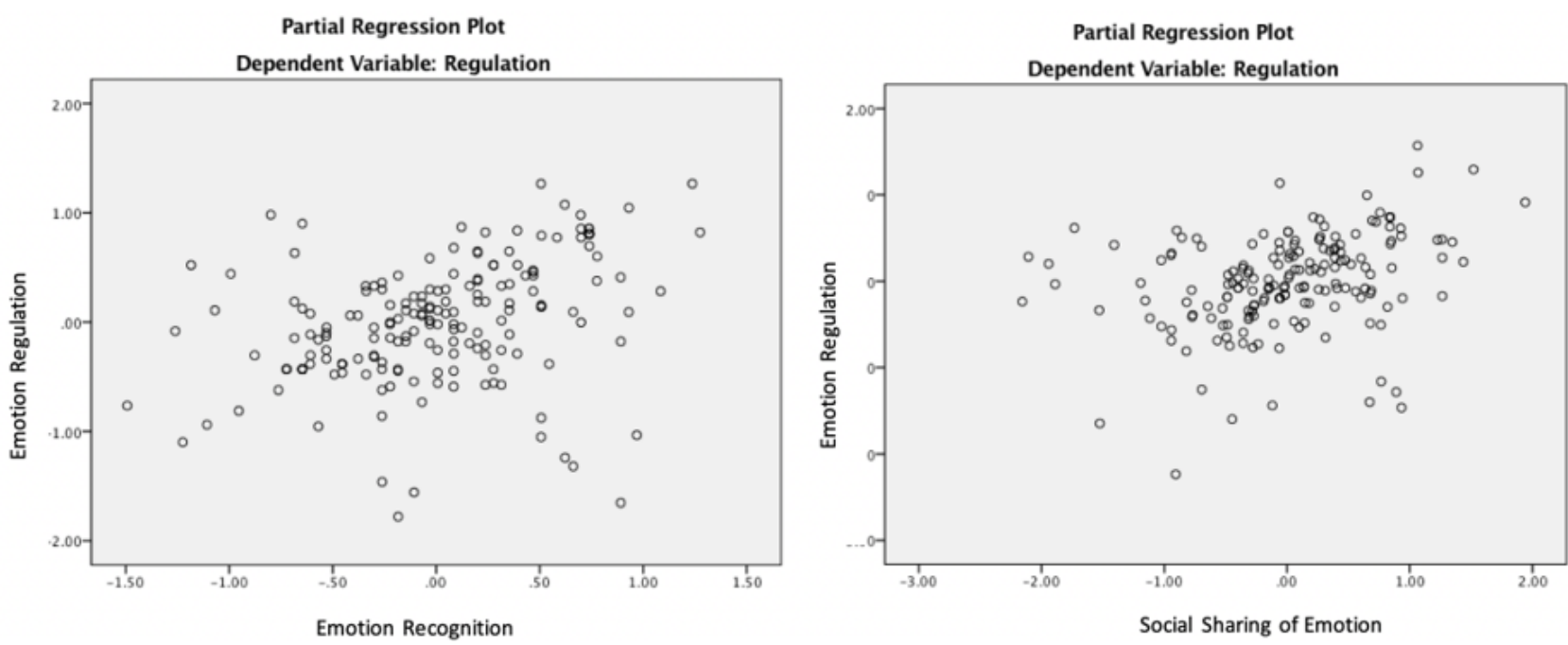

Figure 3. The partial regression plot of emotion regulation

Table 4. $\mathrm{mCSCL}$ applications used based on three variables

\begin{tabular}{lcccccc}
\hline \multirow{2}{*}{ Types of application } & \multicolumn{2}{c}{$\begin{array}{c}\text { Emotion recognition } \\
\text { (n=183) }\end{array}$} & $\begin{array}{c}\text { Social sharing of emotion } \\
(\mathrm{n}=183)\end{array}$ & \multicolumn{2}{c}{$\begin{array}{c}\text { Emotion regulation } \\
(\mathrm{n}=183)\end{array}$} \\
\cline { 2 - 7 } 1. Instant message & $\mathrm{M}$ & $\mathrm{SD}$ & $\mathrm{M}$ & $\mathrm{SD}$ & $\mathrm{M}$ & SD \\
2. Social media & 4.10 & .98 & 4.10 & .97 & 3.84 & 1.04 \\
3. Video & 3.95 & 1.04 & 4.15 & .98 & 3.81 & 1.11 \\
4. Music & 3.93 & .98 & 3.99 & .99 & 3.91 & .96 \\
5. Meetings & 3.91 & 1.01 & 3.97 & .92 & 3.89 & .97 \\
6. Task organizer & 3.96 & .99 & 3.92 & 1.14 & 3.75 & 1.14 \\
7. Brainstorming and ideas & 3.58 & .91 & 3.48 & 1.04 & 3.40 & 1.04 \\
8. Working and storages & 3.60 & .92 & 3.55 & 1.04 & 3.47 & 1.01 \\
9. Write, sketch, \& draw & 3.55 & 1.02 & 3.44 & 1.08 & 3.41 & 1.00 \\
10. Habits tracking & 3.57 & .89 & 3.49 & 1.06 & 3.54 & 1.03 \\
11. Edutainment & 3.50 & .93 & 3.34 & 1.04 & 3.43 & 1.01 \\
12. Games \& entertainment & 3.52 & .96 & 3.46 & 1.02 & 3.38 & .96 \\
13. Activity tracking, health, \& exercise & 3.95 & .98 & 3.91 & .97 & 3.72 & 1.00 \\
14. Meditation \& mindfulness & 3.53 & .91 & 3.52 & .99 & 3.46 & 1.02 \\
15. Shopping \& lifestyle & 3.54 & .95 & 3.44 & 1.00 & 3.45 & 1.04 \\
\hline
\end{tabular}

Emotion regulation $(y)=1.237+.386 \times$ Emotion recognition $+.262 \times$ Social sharing of emotion.

Moreover, we revealed the emotion adjustment techniques regarding emotion recognition, social sharing of emotion, and emotion regulation which can be adapted into computer-supported collaboration. The results fall into three topics: mCSCL applications, activities used for emotion adjustment, and the levels of importance of collaboration regarding the three variables. Firstly, we explored the applications that were used in accordance with the three variables when participants were working based on their goals (Table 4).

On average, instant messaging applications seemed to be the top three applications that were being used among these three variables $(\mathrm{M}=4.10,4.10,3.84, \mathrm{SD}=.98, .97,1.04)$. Otherwise, participants were mainly recognizing the emotions of themselves and others, mostly via meetings and social media $(M=3.96,3.95$, 
Table 5. Activities used for emotions adjustment

\begin{tabular}{lcc}
\hline \multirow{2}{*}{ Baseline activity } & \multicolumn{2}{c}{ Adjusting self-emotions $(\mathrm{n}=183)$} \\
\cline { 2 - 3 } 1. Listening & $\mathrm{M}$ & $\mathrm{SD}$ \\
2. Speaking & 4.32 & .77 \\
3. Reading & 3.68 & .93 \\
4. Writing & 3.70 & .93 \\
5. Kinesthetic & 3.74 & 1.01 \\
6. Changing environments & 4.08 & .91 \\
7. Face to face communication & 4.16 & .88 \\
8. Social network & 3.92 & .91 \\
\hline
\end{tabular}

Table 6. Levels of importance of three variables at different levels of collabor

\begin{tabular}{lcc}
\hline \multirow{2}{*}{ Baseline characteristic } & \multicolumn{2}{c}{ Levels of importance $(\mathrm{n}=183)$} \\
\cline { 2 - 3 } 1. Networking & $\mathrm{M}$ & $\mathrm{SD}$ \\
2. Cooperation & 4.05 & .84 \\
3. Coordination & 4.36 & .83 \\
4. Coalition & 4.28 & .81 \\
5. Collaboration & 4.11 & .87 \\
\hline
\end{tabular}

$\mathrm{SD}=.99,1.04)$. However, they tended to use social media and video to share their emotions with others $(\mathrm{M}=4.15,3.99, \mathrm{SD}=.98, .99)$. For emotion regulation, video and music were the key applications ( $\mathrm{M}=3.91$, $3.81, \mathrm{SD}=.96, .97)$.

Secondly, to answer the question "What kind of activity can be used for your emotion adjustment? (to positive mode)", the results as showed in Table 5, indicated that participants used listening activities the most to adjust their emotion in a positive manner ( $M=4.32, S D=.77)$. Apart from listening, the results showed a dominance in changing the environment and doting the kinesthetic activity $(\mathrm{M}=4.16,4.08, \mathrm{SD}=.88, .91)$ respectively. Social networks ranked fourth $(M=3.99, S D=.86)$, higher than the face-to-face communication $(\mathrm{M}=3.92, \mathrm{SD}=.91)$.

Lastly, according to the data, emotion recognition, social sharing of emotion, and emotion regulation were viewed as the most important factors in cooperation and collaboration levels ( $M=4.36,4.32, S D=.83, .83$ ) Conversely, there is far less importance placed on the lowest hierarchy at a networking level $(M=4.05$, $\mathrm{SD}=.84$.) as depicted in Table. 6.

\section{DISCUSSION}

In the current study, we investigated emotion recognition tools by using an emotion tracker and the physiological signals acquired from mobile and wearable devices. Not surprisingly, these results suggested that most pre-service teachers own at least one of the mobile technologies e.g., smartphone, tablets, and laptops. There was an interesting increase in the number of additional gadgets and wearable devices like EarPods and smart watches. Yet, it is almost impossible to use other methods such as the loT and other wearable devices for the time being. However, we cannot avoid the trend of using wearable devices, taking the form of different accessories and clothing, which will be worn by people in the future. These devices might be expected to continuously collect and upload various physiological data to improve our life (Seneviratne et al., 2017). The range and availability of mobile applications is seen as a means to utilize mobile phone technologies and cultivate related issues like empathy (Papoutsi \& Drigas, 2017).

Furthermore, the process of initiating, maintaining, modulating, and changing of feeling states including emotions and moods is increasingly important in our everyday life (Niven et al., 2011). Our data has also revealed that pre-service teachers mostly use physical signals e.g., expression, voice/speech, and gesture/posture to recognize the emotions of themselves and others. This result may be explained by the fact that there is a lot of extensive research on emotional expression, especially the two subtests of emotion 
recognition ability (facial, vocal). In these two subsets, there is the need for a rapid test of emotion recognition ability (Scherer \& Scherer, 2011). Corresponded to Connolly et al. (2020) significant evidence for an emotion recognition ability factor that exists across visual and auditory domains and includes social signals communicated by face, body, and voice. Among the physiological signals, heart rate (HR) and heart rate variability (HRV) have perceived the most possibility for emotion recognition according to their subjective impression. The findings corresponded to emotion recognition technique in the scientific literature. Emotion detection is currently regarded as a critical machine capability in human-machine communications for emotion detection approaches (Egger et al., 2019).

The present discoveries open the door to the next stage, which is to link the signals obtained from smartphones and wearable devices. For example, there were several attempts to develop emotion identification algorithm on mobile apps (Hossain \& Muhammad, 2017; Kołakowska et al., 2020). Recent studies have tried to initiate the tools used to ex-amine recognition, e.g. RaFD facial recognition tools used among college students (Dores et al., 2020). Another interesting issue is that heart rate (HR) and heart rate variability (HRV) are seen to be the most viable methods out of all the uses of physiological signals. These findings further support the findings of Guo et al. (2016), who used heart rate variability features to detect emotions by using time-domain, frequency-domain, Poincare, and statistical analysis. In addition to this, Shu et al. (2020) used heart rate data from a smart bracelet to detect emotions. Moreover, we have found in the data that text (status, captions, tweets) and chats, photos, and video stories seem to be an alternative. According to the study, participants displayed less agreement when it came to using emoticons, stickers, AR emoji. However, the findings might differ from Scherr et al. (2019), who stated that emoji can be used as a tool for analyzing the users' perspectives to gain feedback.

The main results of this study indicated that emotion recognition, social sharing of emotions, and emotion regulation were found to be statistically significant and the values for all variables across cases were positively correlated. The two-predictor model of emotion recognition and social sharing of emotion was also able to account for a $31 \%$ variance in emotion regulation. The study confirms that emotion recognition and social sharing of emotion is associated with emotion regulation. This finding further supports the work of Heberle et al. (2020) and Järvenoja and Järvelä (2009) who stated that to respond the socio-emotional challenges in collaborative learning, emption is one of the key success factors in which students can learn to regulate emotions both individually and collaboratively. Co-regulation and socially shared regulation are mediated by a computational artifact in CSCL (participant-artifact-participant) (Ludvigsen \& Steier, 2019). However, emotional perception is grounded in the broader process of social interaction (Abramson et al., 2020), and social sharing of emotion can cover the functions of the socio-affective to strengthen social ties (Rimé, 2017).

For mCSCL applications, these results indicated that instant messaging applications (e.g., Messenger, Line, Whatsapp, Wechat, and KakaoTalk) were found to be the top applications that are being used among the three variables. An additional way to recognize their own and other emotions is via meetings (e.g., Facetime, Zoom, Teams, Meet, and Explain Everything), and social media (e.g., Facebook, Instagram, Twitter, Linkedln, and Tiktok). For sharing emotion, pre-service teachers tend to use social media and videos (e.g., YouTube, Video Stories, Live steaming) to share their emotions with others. For emotion regulation purposes, video and music-based applications (e.g., Apple music, Spotify, and Joox Music) were the key methods. Based on this analysis, we determined that the interaction taking place in the $\mathrm{MCSCL}$ is highly necessary in accordance with the feedback provided to the receiver. However, few studies have investigated emotions when they differ by feedback type in various classroom feed-back practices (Fong et al., 2018). An example of this would be affective feedback recorded in a Live Journal which helps cognitive development as well as providing emotional support and empathy (Rodríguez Hidalgo et al., 2015).

Regarding the activities for emotion adjustment, participants mostly use listening activities e.g., listening to music or podcasts to positively adjust their emotions, changing environments (e.g., place, temperature, light, smell) and engaging in kinesthetic activities. These findings are consistent with previous studies which reflected the relationship between visuals (light), auditory factors (sound) and stimuli, and how they affect emotional states (Castillo et al., 2014; Hori et al., 2017). 
Lastly, this study has shown that all three variables are viewed as the most important regarding cooperation and collaboration levels and are less important when it comes to the lowest hierarchy of the networking level. The present study seems to be consistent with the socioemotional selectivity theory (Carstensen, 1992), which highlighted the importance of working closely with social partners via social activities, depending on both the perception of time and age differences. The social sharing of emotion is addressed via members of one's close social network, which in the case of adulthood, spouses and partners are the main sharing targets, followed by family members and friends (Jerčić \& Sundstedt, 2019).

\section{CONCLUSIONS AND RECOMENDATIONS}

This paper argued that the smartphone is the widely used in daily life and, at this current time, wearable devices are not nearly as popular. In future investigations, it might be possible to develop applications on smartphones to support training and to enable pre-service teachers to monitor their own emotion regulation. Our study has shown that students perceived better emotional recognition in face-to-face settings when compared to the virtual settings. However, we seek to contribute to the field of the mobile sensing for emotion detection. Among the biodata, heart rate is perceived to be a "valid" bio-signal for emotional recognition. Students tend to use expression contexts in "chat" and "video" which could bring up a story (context) within an online learning environment. Based upon this analysis, it is considered imperative that for teacher education development, emotion regulation is highly recommended when considering socioaffective factors in which emotion recognition and the social sharing of emotion are the significant predictors. However, this study has generated many issues that require additional examination. One of the limitations with this explanation is that it does not clarify the cognitive perspective. Future research is needed to look into the usage of emotion and how it interacts with the multiple aspects mentioned on the social and cognitive levels. There's also lots of room for growth in determining some of the diverse cultural perspectives, as well as moving on to the next phase of emotion detection with scientific validation.

Author contributions: SW: Original draft, formal analysis, writing, review, and editing; JN-S: Review and editing. All authors approve final version of the article.

Author notes: This work was under the Disruptive Innovation Technology in Education, Chulalongkorn University. The research results were previously presented at AECT 2020 Virtual Convention.

Funding: This research was financially supported by the Royal Golden Jubilee PhD Programme of the Thailand Research Fund (TRF) (Grant No. PHD/0210/2560).

Declaration of interest: Authors declare no competing interest.

Data availability: Data generated or analysed during this study are available from the authors on request.

\section{REFERENCES}

Abramson, L., Petranker, R., Marom, I., \& Aviezer, H. (2020). Social interaction context shapes emotion recognition through body language, not facial expressions. Emotion, 21(3), 557-568. https://doi.org/ 10.1037/emo0000718

Augustsson, G. (2010). Web 2.0, pedagogical support for reflexive and emotional social interaction among Swedish students. The Internet and Higher Education, 13(4), 197-205. https://doi.org/10.1016/j. iheduc.2010.05.005

Bucich, M., \& MacCann, C. (2019). Emotional intelligence and day-to-day emotion regulation processes: Examining motives for social sharing. Personality and Individual Differences, 137, 22-26. https://doi.org/10.1016/j.paid.2018.08.002

Butler, E. A., \& Gross, J. J. (2009). Emotion and emotion regulation: Integrating individual and social levels of analysis. Emotion Review, 1(1), 86-87. https://doi.org/10.1177/1754073908099131

Carstensen, L. L. (1992). Social and emotional patterns in adulthood: Support for socioemotional selectivity theory. Psychology and Aging, 7(3), 331-338. https://doi.org/10.1037/0882-7974.7.3.331 
Carstensen, L. L., Fung, H. H., \& Charles, S. T. (2003). Socioemotional selectivity theory and the regulation of emotion in the second half of life. Motivation and Emotion, 27(2), 103-123. https://doi.org/10.1023/ a:1024569803230

Castillo, J. C., Fernández-Caballero, A., Castro-González, Á., Salichs, M. A., \& López, M. T. (2014). A framework for recognizing and regulating emotions in the elderly. In L. Pecchia, L.L. Chen, C. Nugent, \& J. Bravo (Eds.), Ambient assisted living and daily activities (pp. 320-327). Springer. https://doi.org/10.1007/9783-319-13105-4_46

Connolly, H. L., Lefevre, C. E., Young, A. W., \& Lewis, G. J. (2020). Emotion recognition ability: Evidence for a supramodal factor and its links to social cognition. Cognition, 197, 104166. https://doi.org/10.1016/ j.cognition.2019.104166

Cowie, R., Douglas-Cowie, E., Tsapatsoulis, N., Votsis, G., Kollias, S., Fellenz, W., \& Taylor, J. G. (2001). Emotion recognition in human-computer interaction. IEEE Signal Processing Magazine, 18(1), 32-80. https://doi.org/10.1109/79.911197

Dores, A. R., Barbosa, F., Queirós, C., Carvalho, I. P., \& Griffiths, M. D. (2020). Recognizing emotions through facial expressions: A largescale experimental study. International Journal of Environmental Research and Public Health, 17(20), 7420. https://doi.org/10.3390/ijerph17207420

Dudley, N. M., \& Multhaup, K. S. (2005). When familiar social partners are selected in open-ended situations: Further tests of the socioemotional selectivity theory. Experimental Aging Research, 31(3), 331-344. https://doi.org/10.1080/03610730590948212

Egger, M., Ley, M., \& Hanke, S. (2019). Emotion recognition from physiological signal analysis: A review. Electronic Notes in Theoretical Computer Science, 343, 35-55. https://doi.org/10.1016/j.entcs.2019.04. 009

Fong, C. J., Williams, K. M., Williamson, Z. H., Lin, S., Kim, Y. W., \& Schallert, D. L. (2018). "Inside out": Appraisals for achievement emotions from constructive, positive, and negative feedback on writing. Motivation and Emotion, 42(2), 236-257. https://doi.org/10.1007/s11031-017-9658-y

Frey, B. B., Lohmeier, J. H., Lee, S. W., \& Tollefson, N. (2006). Measuring collaboration among grant partners. American Journal of Evaluation, 27(3), 383-392. https://doi.org/10.1177/1098214006290356

Garnefski, N., \& Kraaij, V. (2006). Cognitive emotion regulation questionnaire-development of a short 18item version (CERQ-short). Personality and Individual Differences, 41(6), 1045-1053. https://doi.org/ 10.1016/j.paid.2006.04.010

Gross, J. J. (2015). The extended process model of emotion regulation: Elaborations, applications, and future directions. Psychological Inquiry, 26(1), 130-137. https://doi.org/10.1080/1047840X.2015.989751

Guo, H., Huang, Y., Lin, C., Chien, J., Haraikawa, K., \& Shieh, J. (2016, 31 Oct.-2 Nov. 2016). Heart rate variability signal features for emotion recognition by using principal component analysis and support vectors machine [Paper presentation]. 2016 IEEE 16th International Conference on Bioinformatics and Bioengineering, Taichung, Taiwan. https://doi.org/10.1109/BIBE.2016.40

Heberle, A. E., Thomann, C. R. B., \& Carter, A. S. (2020). Social and emotional development theories. Elsevier. https://doi.org/10.1016/B978-0-12-809324-5.23633-X

Hofmann, S. G., Carpenter, J. K., \& Curtiss, J. (2016). Interpersonal emotion regulation questionnaire (IERQ): Scale development and psychometric characteristics. Cognitive Therapy and Research, 40(3), 341-356. https://doi.org/10.1007/s10608-016-9756-2

Hori, S., Mori, K., Mashimo, T., \& Seiyama, A. (2017). Effects of light and sound on the prefrontal cortex activation and emotional function: A functional near-infrared spectroscopy study. Frontiers in Neuroscience, 11, 321. https://doi.org/10.3389/fnins.2017.00321 
Hossain, M. S., \& Muhammad, G. (2017). An emotion recognition system for mobile applications. IEEE Access, 5, 2281-2287. https://doi.org/10.1109/ACCESS.2017.2672829

Hsu, Y.-C., \& Ching, Y.-H. (2013). Mobile computer-supported collaborative learning: A review of experimental research. British Journal of Educational Technology, 44(5), E111-E114. https://doi.org/ 10.1111/bjet.12002

Järvenoja, H., \& Järvelä, S. (2009). Emotion control in collaborative learning situations: Do students regulate emotions evoked by social challenges. British Journal of Educational Psychology, 79(3), 463-481. https://doi.org/10.1348/000709909x402811

Jeong, H., Hmelo-Silver, C. E., \& Jo, K. (2019). Ten years of computer-supported collaborative learning: A meta-analysis of CSCL in STEM education during 2005-2014. Educational Research Review, 28, 100284. https://doi.org/10.1016/j.edurev.2019.100284

Jerčić, P., \& Sundstedt, V. (2019). Practicing emotion-regulation through biofeedback on the decision-making performance in the context of serious games: A systematic review. Entertainment Computing, 29, 7586. https://doi.org/10.1016/j.entcom.2019.01.001

Kearney, M., \& Maher, D. (2019). Mobile learning in pre-service teacher education: Examining the use of professional learning networks. Australasian Journal of Educational Technology, 35(1), 135-148. https://doi.org/10.14742/ajet.4073

Keller, M. M., \& Becker, E. S. (2020). Teachers' emotions and emotional authenticity: do they matter to students' emotional responses in the classroom? Teachers and Teaching, 27(5), 404-422. https://doi.org/10.1080/13540602.2020.1834380

Kołakowska, A., Landowska, A., Szwoch, M., Szwoch, W., \& Wróbel, M. R. (2014). Emotion recognition and its applications. In Z. S. Hippe, J. L. Kulikowski, T. Mroczek, \& J. Wtorek (Eds.), Human-computer systems interaction: Backgrounds and applications 3 (pp. 51-62). Springer. https://doi.org/10.1007/978-3-31908491-6_5

Kołakowska, A., Szwoch, W., \& Szwoch, M. (2020). A review of emotion recognition methods based on data acquired via smartphone sensors. Sensors, 20(21), 6367. https://doi.org/10.3390/s20216367

Liu, C., Wan, P., Hwang, G.-J., Tu, Y.-F., \& Wang, Y. (2021). From competition to social interaction: A mobile team-based competition approach to promoting students' professional identity and perceptions. Interactive Learning Environments, 1-15. https://doi.org/10.1080/10494820.2020.1823855

Ludvigsen, S. (2016). CSCL: Connecting the social, emotional and cognitive dimensions. International Journal of Computer-Supported Collaborative Learning, 11(2), 115-121. https://doi.org/10.1007/s11412-0169236-4

Ludvigsen, S., \& Steier, R. (2019). Reflections and looking ahead for CSCL: Digital infrastructures, digital tools, and collaborative learning. International Journal of Computer-Supported Collaborative Learning, 14(4), 415-423. https://doi.org/10.1007/s11412-019-09312-3

Lyusin, D., \& Ovsyannikova, V. (2016). Measuring two aspects of emotion recognition ability: Accuracy vs. sensitivity. Learning and Individual Differences, 52, 129-136. https://doi.org/10.1016/j.lindif.2015.04. 010

Mayer, J. D., Caruso, D. R., \& Salovey, P. (2016). The ability model of emotional intelligence: Principles and updates. Emotion Review, 8(4), 290-300. https://doi.org/10.1177/1754073916639667

Miller, M., \& Hadwin, A. (2015). Scripting and awareness tools for regulating collaborative learning: Changing the landscape of support in CSCL. Computers in Human Behavior, 52, 573-588. https://doi.org/10. 1016/j.chb.2015.01.050 
Molinari, G., Chanel, G., Betrancourt, M., Pun, T., \& Bozelle Giroud, C. (2013). Emotion feedback during computer-mediated collaboration: Effects on self-reported emotions and perceived interaction. In N. Rummel, M. Kapur, M. Nathan, \& S. Puntambekar (Eds.), To see the world and a grain of sand: Learning across levels of space, time, and scale: CSCL 2013 conference proceedings volume 1-Full papers \& symposia (pp. 336-343). Madison, WI, USA.

Nasoz, F., Alvarez, K., Lisetti, C., \& Finkelstein, N. (2003). Emotion recognition from physiological signals for presence technologies. International Journal of Cognition, Technology, and Work-Special Issue on Presence, 6(1), 1-32. https://doi.org/10.1007/s10111-003-0143-x

National Statistical Office. (2020). The use of ICT among the people of Thailand in 2020. http://www.nso.go.th/sites/2014/Lists/Infographic/Attachments/101/Infographic_ICT63.pdf

Näykki, P., Isohätälä, J., Järvelä, S., Pöysä-Tarhonen, J., \& Häkkinen, P. (2017). Facilitating socio-cognitive and socio-emotional monitoring in collaborative learning with a regulation macro script-an exploratory study. International Journal of Computer-Supported Collaborative Learning, 12(3), 251-279. https://doi.org/10.1007/s11412-017-9259-5

Niven, K., Totterdell, P., Stride, C. B., \& Holman, D. (2011). Emotion regulation of others and self (EROS): The development and validation of a new individual difference measure. Current Psychology, 30, 53-73. https://doi.org/10.1007/s12144-011-9099-9

Papoutsi, C., \& Drigas, A. (2017). Empathy and mobile applications. International Journal of Interactive Mobile Technologies, 11(3), 57-66. https://doi.org/10.3991/ijim.v11i3.6385

Preece, D. A., Becerra, R., Robinson, K., Dandy, J., \& Allan, A. (2018). Measuring emotion regulation ability across negative and positive emotions: The Perth emotion regulation competency inventory (PERCI). Personality and Individual Differences, 135, 229-241. https://doi.org/10.1016/j.paid.2018.07.025

Resta, P., \& Laferrière, T. (2007). Technology in support of collaborative learning. Educational Psychology Review, 19(1), 65-83. https://doi.org/10.1007/s10648-007-9042-7

Rimé, B. (2009). Emotion elicits the social sharing of emotion: Theory and empirical review. Emotion Review, 1(1), 60-85. https://doi.org/10.1177/1754073908097189

Rimé, B. (2017). The social sharing of emotion in interpersonal and in collective situations. In J. A. Holyst (Ed.), Cyberemotions: Collective emotions in cyberspace (pp. 53-69). Springer. https://doi.org/10.1007/9783-319-43639-5_4

Rimé, B., Finkenauer, C., Luminet, O., Zech, E., \& Philippot, P. (1998). Social sharing of emotion: New evidence and new questions. European Review of Social Psychology, 9(1), 145-189. https://doi.org/10.1080/ 14792779843000072

Rodríguez Hidalgo, C. T., Tan, E. S. H., \& Verlegh, P. W. J. (2015). The social sharing of emotion (SSE) in online social networks: A case study in Live Journal. Computers in Human Behavior, 52, 364-372. https://doi.org/10.1016/j.chb.2015.05.009

Salovey, P., \& Mayer, J. D. (1990). Emotional intelligence. Imagination, Cognition, and Personality, 9(3), 185211. https://doi.org/10.2190/DUGG-P24E-52WK-6CDG

Sarprasatham, M. (2015). Emotion recognition: A survey. International Journal of Advanced Research in Computer Science, 3, 14-19.

Scherer, K. R., \& Scherer, U. (2011). Assessing the ability to recognize facial and vocal expressions of emotion: Construction and validation of the emotion recognition index. Journal of Nonverbal Behavior, 35(4), 305. https://doi.org/10.1007/s10919-011-0115-4 
Scherr, S. A., Polst, S., Müller, L., Holl, K., \& Elberzhager, F. (2019). The perception of emojis for analyzing app feedback. International Journal of Interactive Mobile Technologies, 13(2), 19-36. https://doi.org/10.3991/ijim.v13i02.8492

Schutte, N. S., Malouff, J. M., Hall, L. E., Haggerty, D. J., Cooper, J. T., Golden, C. J., \& Dornheim, L. (1998). Development and validation of a measure of emotional intelligence. Personality and Individual Differences, 25(2), 167-177. https://doi.org/10.1016/S0191-8869(98)00001-4

Seneviratne, S., Hu, Y., Nguyen, T., Lan, G., Khalifa, S., Thilakarathna, K., Hassan, M., \& Seneviratne, A. (2017). A survey of wearable devices and challenges. IEEE Communications Surveys \& Tutorials, 19(4), 25732620. https://doi.org/10.1109/COMST.2017.2731979

Shu, L., Xie, J., Yang, M., Li, Z., Li, Z., Liao, D., Xu, X., \& Yang, X. (2018). A review of emotion recognition using physiological signals. Sensors, 18(7), 2074. https://doi.org/10.3390/s18072074

Shu, L., Yu, Y., Chen, W., Hua, H., Li, Q., Jin, J., \& Xu, X. (2020). Wearable emotion recognition using heart rate data from a smart bracelet. Sensors, 20(3), 718. https://doi.org/10.3390/s20030718

Sung, Y.-T., Yang, J.-M., \& Lee, H.-Y. (2017). The effects of mobile-computer-supported collaborative learning: Meta-analysis and critical synthesis. Review of Educational Research, 87(4), 768-805. https://doi.org/ 10.3102/0034654317704307

Suthers, D. D. (2012). Computer-supported collaborative learning. In N. M. Seel (Ed.), Encyclopedia of the sciences of learning (pp. 719-722). Springer. https://doi.org/10.1007/978-1-4419-1428-6_389

Thompson, R. A., Meyer, S., \& Jochem, R. (2008). Emotion regulation. In M. M. Haith, \& J. B. Benson (Eds.), Encyclopedia of infant and early childhood development (pp. 431-441). Academic Press. https://doi.org/10.1016/B978-012370877-9.00055-4

Zaki, J., \& Williams, W. C. (2013). Interpersonal emotion regulation. Emotion, 13(5), 803-810. https://doi.org/ $10.1037 / \mathrm{a} 0033839$

Zelkowitz, R. L., \& Cole, D. A. (2016). Measures of emotion reactivity and emotion regulation: Convergent and discriminant validity. Personality and Individual Differences, 102, 123-132. https://doi.org/10.1016 /j.paid.2016.06.045

Correspondence: Jaitip Na-Songkhla, Faculty of Education, Chulalongkorn University, Thailand.

E-mail: Jaitip.n@chula.ac.th 